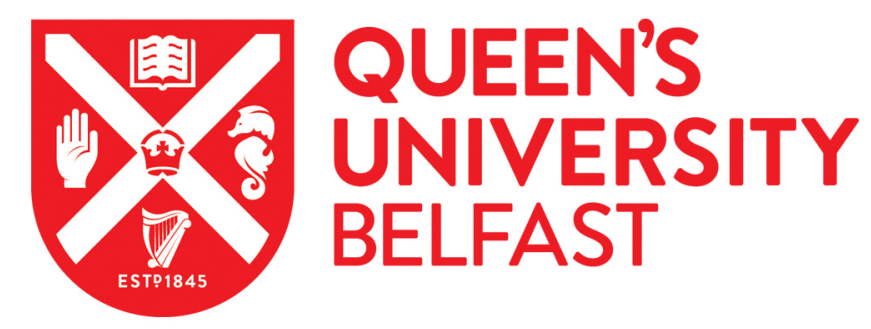

\title{
Impacts of global change on species distributions: obstacles and solutions to integrate climate and land use
}

Sirami, C., Caplat, P., Popy, S., Clamens, A., Arlettaz, R., Jiguet, F., Brotons, L., \& Martin, J. L. (2017). Impacts of global change on species distributions: obstacles and solutions to integrate climate and land use. Global Ecology \& Biogeography, 26(4), 385-394. https://doi.org/10.1111/geb.12555

Published in:

Global Ecology \& Biogeography

Document Version:

Peer reviewed version

Queen's University Belfast - Research Portal:

Link to publication record in Queen's University Belfast Research Portal

Publisher rights

(c) 2016 John Wiley \& Sons Ltd

This is the peer reviewed version of the following articleSirami, C., Caplat, P., Popy, S., Clamens, A., Arlettaz, R., Jiguet, F., Brotons, L., Martin, J.-L. (2016), Impacts of global change on species distributions: obstacles and solutions to integrate climate and land use. Global Ecology and Biogeography, which has been published in final form at http://onlinelibrary.wiley.com/wol1/doi/10.1111/geb.12555/abstract. This article may be used for non-commercial purposes in accordance with Wiley Terms and Conditions for Self-Archiving

\section{General rights}

Copyright for the publications made accessible via the Queen's University Belfast Research Portal is retained by the author(s) and / or other copyright owners and it is a condition of accessing these publications that users recognise and abide by the legal requirements associated with these rights.

\section{Take down policy}

The Research Portal is Queen's institutional repository that provides access to Queen's research output. Every effort has been made to ensure that content in the Research Portal does not infringe any person's rights, or applicable UK laws. If you discover content in the Research Portal that you believe breaches copyright or violates any law, please contact openaccess@qub.ac.uk. 
1 Global change impacts on species distributions: obstacles and solutions to integrate climate and

2 land use

3

4 Clélia Sirami $^{1 *}$, Paul Caplat ${ }^{2}$, Simon Popy ${ }^{1}$, Alex Clamens ${ }^{3}$, Raphaël Arlettaz ${ }^{4,5}$, Frédéric Jiguet $^{6}$, 5 Lluís Brotons ${ }^{7,8,9}$, Jean-Louis Martin ${ }^{1}$

6

$7{ }^{1}$ Centre d'écologie fonctionnelle et évolutive U.M.R. 5175 - CNRS - Université de Montpellier -

8 Université Paul Valéry - EPHE, 1919 route de Mende, 34293 Montpellier Cedex, France,

$9 \quad{ }^{2}$ Centre for Environmental and Climate Research, Lund University, Lund, Sweden,

$10{ }^{3}$ Lycée Blaise Pascal 36 avenue Carnot 63037 Clermont-Ferrand Cedex 1, France,

$11{ }^{4}$ Institute of Ecology and Evolution, Division of Conservation Biology, Baltzerstrasse 6, CH-3012

12 Bern, Switzerland,

${ }^{5}$ Swiss Ornithological Institute, Valais Field Station, Rue du Rhône 11, CH-1950 Sion, Switzerland,

$14{ }^{6}$ CESCO, UMR 7204 Sorbonne Universités-MNHN-CNRS-UPMC, CP 135, 43 rue Buffon, 75005

15 Paris Cedex, France,

${ }^{7}$ InForest Jru (CEMFOR-CTFC-CREAF), Solsona, 25280, Spain,

${ }^{8}$ CREAF, 08193 Cerdanyola del Vallés, Spain

${ }^{9}$ CSIC, 08193 Cerdanyola del Vallés, Spain

*Present address and correspondence: Clélia Sirami, INRA UMR1201 DYNAFOR, 31320

Castanet-Tolosan, France. E-mail: clelia.sirami@toulouse.inra.fr Tel: +33 (0) 561285351

Keywords: land-use change, climate change, synergies, antagonisms, range shift, community indices

Running title: Land-use and climate change integration

Number of words in the Abstract: 278

Number of words in main body of the paper: 2804

Number of references: 66 
32 Aim The impact of multiple stressors on biodiversity is one of the most pressing questions in ecology and biodiversity conservation. We here critically assess how often and efficiently the two main drivers of global changes have been simultaneously integrated into research, with the aim to provide practical solutions for better integration in the future. We focus on the integration of climate change (CC) and land-use change (LUC) when studying changes in species distributions.

\section{Location Global}

Methods We analysed the peer-reviewed literature on the effects of CC and LUC on observed changes in species distributions, i.e. including species range and abundance, between 2000 and 2014.

Results Studies integrating CC and LUC remain extremely scarce, which hampers our ability to develop appropriate conservation strategies. The lack of CC-LUC integration is likely to be resulting from insufficient recognition of the co-occurrence of CC and LUC at all scales, co-variation and interactions between CC and LUC, as well as correlations between species thermal and habitat requirements. Practical guidelines to study these interactive effects include considering multiple drivers and processes when designing studies, using available long-term datasets on multiple drivers, revisiting single-driver studies with additional drivers or conducting comparative studies and metaanalyses. Combining various methodological approaches, including time lags and adaptation processes represent further avenues to improve global change science.

Main conclusions Despite repeated claims for a better integration of multiple drivers, CC and LUC effects on species distributions and abundances have been mostly studied in isolation, which calls for a shift of standards towards more integrative global change science. The guidelines proposed here will encourage study designs that account for multiple drivers and improve our understanding of synergies or antagonisms among drivers. 
Over the past decades, the challenges to biodiversity presented by climate change (CC) have triggered exponential growth in the literature on the current and predicted CC impacts on populations, species and ecological communities (e.g. Parmesan and Yohe, 2003). Evidence shows that ecosystems have already been greatly affected and that impacts will continue mostly unabated. What we still largely ignore is the magnitude of these past and, above all, future impacts (Hansen et al., 2015).

Most studies on the impact of CC on species distributions have shown that species vary greatly in their responses (e.g. Parmesan and Yohe, 2003). This heterogeneity in responses reflects differences in species sensitivity to climate (Angert et al., 2011). However, interactions amongst multiple global change drivers have recently been identified as a major cause of uncertainty in CC attribution (Parmesan et al., 2013) and CC projection (de Chazal and Rounsevell, 2009).

Despite repeated calls for a better integration of multiple drivers (de Chazal and Rounsevell, 2009; Didham et al., 2007; Mantyka-pringle et al., 2012; Oliver and Morecroft, 2014; Parmesan et al., 2013), several authors have highlighted that conventional CC investigations and projections privileging CC attribution remain the norm (Oliver and Morecroft, 2014; Titeux et al., 2016). In the absence of integrative multi-driver approaches, limited understanding of how interactions among drivers affect observed changes will likely hamper reliable projections and relevant conservation recommendations (Titeux et al., 2016).

To identify obstacles towards integrating drivers and ways to overcome them, we analysed how CC and land-use change (LUC) impacts on species distributions have been, and could be, studied. Our aim was to provide a pragmatic approach to that challenge (Oliver and Morecroft, 2014; Parmesan et al., 2013). We therefore addressed four questions: 1) What is the degree of CC-LUC integration in published studies on changes in species distributions? 2) What are the consequences of insufficient integration of drivers? 3) What factors might limit CC-LUC integration? 4) How can integrative studies of CC-LUC effects on species distributions be promoted? 


\section{Current CC-LUC integration in studies of species distribution}

82

We analysed the peer-reviewed literature in three steps. First, we searched Web of Science (http://www.webofknowledge.com) for publications over the 2000-2014 period, on the effects of either CC (temperature and rainfall), LUC or both, on observed or projected changes in species distributions (i.e. species ranges and abundances) in terrestrial ecosystems (see complete list of keywords used for each criterion in Table 1). Second, we read the abstract of all publications on the effects of both CC and LUC on observed changes in species distributions. We then qualitatively assessed the level of driver integration in any given relevant publication based on its abstract. Finally, we read the full text of all publications truly designed to integrate both drivers and assessed their outcome. For the second and third steps, we also included publications on the effects of both CC and LUC on observed changes in species distributions from 2015 and 2016.

Increase in the proportion of CC-only studies - We found 15,593 publications on CC or LUC and species distributions. We observed an increasing number of papers published per year for all types of publications, a pattern reminiscent of the period's general publication trends. Between 2000 and 2005, publications on CC and publications on LUC increased at a similar pace (Figure 1). We detected a steeper increase in the number of CC publications relative to LUC publications after 2005. Currently, there are more than three times more publications on CC than on LUC for projected changes and twice more publications on CC than on LUC for observed changes. The proportion of publications including both CC and LUC almost doubled after 2005 but remained around 12-14\% of the total on that theme, suggesting limited CC-LUC integration regardless of whether the study focused on observed or projected changes (Figure 1).

Poor levels of true integration - We identified four levels of integration based on the abstract of the 158 publications that included both the effects of CC and LUC on observed changes in species distributions (Figure 2). Most studies (72\%) mentioned CC and LUC only as a general context while focusing on a single driver (context only), or acknowledged that other drivers could influence observed changes (acknowledgement). Some studies (20\%) attempted to control for potential 
confounding effects of CC and LUC on species distribution (integration attempt), for example by accounting for species habitat as a covariate in studies on the impact of CC or by selecting study sites without LUC (e.g. Franco et al., 2006; Popy et al., 2010; Reif et al., 2008). Only 8\% of studies were specifically designed to assess the effects of both CC and LUC on species distribution (true integration; e.g. Eglington and Pearce-Higgins, 2012; Fox et al., 2014; Kampichler et al., 2012). This suggests a proportion of integrative studies even lower than what was suggested by our quantitative analysis, with truly integrative studies representing only a tiny fraction of studies on observed changes in species distributions.

Integration revealing hidden driver or combination of drivers - Most of the 13 studies designed to assess the effect of both drivers were published over the last five years. These integrative studies were of three types (see box 1 for more details). A first set showed that, in some cases, despite strong expectations that observed changes were driven by CC, the effects of LUC clearly overrode those of CC (Ameztegui et al., 2016; Bodin et al., 2013; Eglington and Pearce-Higgins, 2012;

O’Connor et al., 2014). A second set showed that the impacts of CC and LUC differed among species groups, some species responding only to CC whereas others were only impacted by LUC (Fox et al., 2014; Hockey et al., 2011; Kampichler et al., 2012; Lavergne et al., 2006). Finally, a third set showed that LUC and CC acted in synergy (Christie et al., 2015; Cunningham et al., 2016; Lunney et al., 2014; Paprocki et al., 2015; Porzig et al., 2014). None of the studies assessing both CC and LUC concluded that only CC had an impact on species distributions. This suggests that the lack of CC-LUC integration is currently jeopardizing our understanding of global change impacts on species distribution (i.e. which driver is having an impact, where, when and why).

\section{Consequences of poor CC-LUC integration in studies on species distributions}

Our analysis of the literature suggests that the lack of CC-LUC integration in studies on species distributions and the dominance of CC-only studies is likely to result in inappropriate management 
strategies or missed conservation opportunities, and may even trigger, in some cases, a relaxation in appropriate conservation efforts.

Overemphasis on connectivity - The lack of CC-LUC integration implies that biodiversity management strategies essentially derive from CC-only studies, which mainly recommend to increase landscape and habitat connectivity (Heller and Zavaleta, 2009). Yet, focusing on the restoration of corridors, stepping stones or 'softening' of the anthropogenic matrix may divert attention away from the primary objective of maintaining habitat area (Hodgson et al., 2009). Moreover, a 'blind’ increase in connectivity based on patterns observed at the community level or at large scales while neglecting the local context or habitat requirements of specialist species, may also fragment other habitats, favour species invasions and/or decrease species adaptive potential (Caplat et al., 2016). For example, open habitat species already negatively affected by woody vegetation encroachment following farmland abandonment (e.g. in the Mediterranean; Sirami et al., 2008) may be further affected by the systematic creation of undisturbed wooded corridors (Eggers et al., 2010).

Missed conservation opportunities - The lack of CC-LUC integration hinders our ability to identify relevant drivers of changes in species distributions, to appropriately project future trends, and therefore to provide efficient conservation recommendations. Moreover, it prevents us from detecting antagonistic CC-LUC effects and therefore from mitigating adverse CC effects through adaptive landuse management (Gaüzère et al., 2016; Princé et al., 2015). For example, Braunisch et al. (2014) showed that expected CC-driven range contractions of mountain forest birds could be partly compensated by enhancing forest structural complexity. The dominance of both LUC-only and CConly studies is therefore likely to hamper the development of effective conservation strategies (but see Faleiro et al., 2013).

Insufficient conservation efforts - Finally, the lack of CC-LUC integration and the dominance of CC-only studies assessing observed shifts in species distribution is likely to have resulted in overrating the effects of CC and downplaying the negative effects of LUC. This is likely to divert funds and efforts away from more immediate conservation priorities (Maxwell et al., 2016). 
The risk of insufficient local conservation efforts is extremely acute for species declines inaccurately attributed to CC (e.g. Hockey and Midgley, 2009) but also concerns most situations where CC and LUC interact (Mantyka-pringle et al., 2012).

\section{Reasons for poor CC-LUC's integration in studies on species distributions}

Our analysis of the literature suggested that, although LUC data and LUC scenario availability and credibility may have been a limiting factor initially (before the 2000s; e.g. Verburg et al., 2002), it fails to explain the recent lack of CC-LUC integration and the increase of CC-only studies. Our review of papers designed to study CC-LUC integration (section 1) and other papers calling for more CC-LUC integration (e.g. de Chazal and Rounsevell, 2009; Oliver and Morecroft, 2014; Parmesan et al., 2013; Titeux et al., 2016) have highlighted three reasons likely to explain the ongoing lack of CCLUC integration, for both observed and projected changes in species distributions.

Misrepresentation of the scale of CC and LUC impacts - The ongoing lack of CC-LUC integration can first be explained by the fact that CC has been expected to impact species distributions at broader spatial and temporal scales (regional-continental, >50 years) and LUC at finer (habitatlandscape, <20 years; Parmesan et al., 2013). This has resulted in the assumptions that CC overrides LUC at regional scales (Thuiller et al., 2004), and that LUC overrides CC at local scales (Bailey et al., 2002). CC has been recently shown to affect species distributions not only through broad latitudinalaltitudinal temperature shifts, but also via progressive shifts in local climate (Lenoir and Svenning, 2015). Conversely, LUC has been shown to massively impact contemporaneous broad scale changes in species distributions (e.g. Barbet-Massin et al., 2012).

\section{Lack of recognition of covariations and interactions between CC and LUC - Partly as a} consequence of the misrepresentation previously described, most studies on latitudinal or altitudinal species shifts focused on CC only, whereas most studies on local long-term changes in species abundance focused on LUC only. However, geographic variation in land cover is highly correlated with geographic variation in bioclimatic variables (e.g. Thuiller et al., 2004) and altitudinal gradients 
are often correlated with land-use intensity gradients (e.g. Archaux, 2004). This implies that LUC represents a likely driver to latitudinal or altitudinal species shifts, habitat gains explaining range expansion (e.g. Elmhagen et al., 2015) and habitat losses explaining range contraction (e.g. Franco et al., 2006). Similarly, CC represents a likely driver to explain local long-term changes in species abundance and community composition (e.g. Lemoine et al., 2007). Moreover, interactions between CC and LUC are likely to be the norm rather than the exception (Parmesan et al., 2013). For example, land cover influences microclimate, and therefore the local effects of CC (e.g. Carlson and Traci Arthur, 2000); landscape structure affects the ability of species to shift their distribution (e.g. Hill et al., 2001); and climate affects the effects of habitat loss (e.g. Mantyka-pringle et al., 2012).

\section{Lack of recognition of correlations between species' thermal and habitat requirements -}

Finally, species' thermal optimum and habitats have repeatedly been used to assess the effects of CC and LUC respectively (e.g. Lemoine et al., 2007). However, climate is the major driver of both species and land-cover distributions, e.g. across Europe (Thuiller et al., 2004). As a result, species' thermal and habitat requirements may equally be influenced by climate and land use. For example, in the Mediterranean, forest bird species have more northern distributions and colder thermal optima than open habitat bird species (Suarez-Seoane et al., 2002). As a result, species traits and community indicators based on thermal requirements only, or habitat associations only, do not constitute a reliable way to disentangle the effects of CC and LUC, unless potential correlations between the effects of these two drivers are explicitly recognized, or their respective causal effects disentangled (Clavero et al., 2011).

\section{Recommendations for future research on CC-LUC interactions}

Building on the obstacles for CC-LUC integration identified here (section 3), and solutions developed in studies that have genuinely integrated CC and LUC (section 1), we propose three main recommendations to design a more effective integrative global-change science (see synthesis and illustration in Figure 3). 
1. Consider multiple drivers at any scale - When working at broad spatial scales, consider potential

211 broad scale gradients in drivers other than CC, in particular LUC (e.g. the South-North LUC gradient

212 in Europe or LUC gradients in the US; Ordonez et al., 2014). The availability of data on past LUC/CC

213 (e.g. Wang et al., 2015) and LUC scenarios (e.g. Stürck et al., 2015) at various scales should facilitate

214 this integration. When working at local scales, account for local processes such as LUC or species invasions as well as fine-grained spatio-temporal variation in temperature and precipitation patterns (e.g. Eglington and Pearce-Higgins, 2012). The availability of long-term climatic and remote-sensing data should facilitate this integration. Most local studies in the literature considered only one driver, but the increased availability of data on other drivers offers new avenues for integrative analyses. These studies could therefore be revisited from a multiple-driver perspective, with the novel integration of two or possibly more drivers (e.g. Benning et al., 2002), for example by comparing existing long-term datasets and new datasets available on CC and LUC (e.g. Péron and Altwegg, 2015).

2. Assess interactions among multiple drivers - Changes in species distributions are likely to result from multiple interacting drivers, resulting in synergies and antagonisms. National monitoring schemes (e.g. the National Ecological Observatory Network, NEON) and international initiatives (e.g. the Group on Earth Observations - Biodiversity Observation Network, GEO BON) represent valuable datasets to assess the complex interactive effects of multiple drivers (Oliver and Morecroft, 2014). Comparing local studies conducted in regions with uncorrelated CC and LUC may also provide a suitable framework for disentangling the effects of the two drivers and assessing their interactions (e.g. within formal meta-analysis; Mantyka-pringle et al., 2012; Parmesan et al., 2013). Finally, whenever possible, we recommend using the methods recently developed to better account for multiple processes, for example by analysing distribution changes along multiple metrics (e.g. Lenoir and Svenning, 2015), quantifying change along multiple gradients (e.g. Tayleur et al., 2015), combining short-term and long-term data with species attributes and environmental variables (e.g. Jørgensen et al., 2016), or integrating key aspects of population dynamics and habitat preferences in models (e.g. Pagel and Schurr, 2012). 
238 thermal optimum or latitudinal distribution and species habitat requirements may be correlated.

239 Comparing distribution changes among species with diverse habitat requirements, uncorrelated with

240 their thermal requirements, or species with diverse range limits, uncorrelated with land cover limits,

241 may be a good approach (e.g. Konvicka et al., 2003). Another solution could be to expand hypotheses

242 on CC indicators to LUC in order to develop novel indicators allowing to quantify the respective roles

243 of, and interactions between, multiple drivers (e.g. Kampichler et al., 2012). Finally, there is now

244 considerable evidence that species respond with varying time-lags to LUC and CC (Kuussaari et al.,

245 2009; Menéndez et al., 2006), which is likely to impede our understanding of species requirements,

246 and, as a result, our understanding of the interactive effects of CC and LUC. There are also subtle

247 interplays between the time species need to adapt to changes and the pace of the evolutionary

248 processes shaping their distributions (e.g. plant dispersal evolution; Caplat et al., 2013).

249 Consequently, to better assess the interactive effects of multiple drivers on species distribution, we

250 recommend, if possible, to 1) consider time-lags in species response to environmental changes; 2) use

251 long-term data to check for interactions between environmental drivers and population dynamics (e.g.

252 Wittwer et al., 2015), and 3) reinforce the links between macro-ecological studies and macroevolution

253 (e.g. Lancaster et al., 2015; Lavergne et al., 2013) .

\section{Conclusion}

Despite repeated calls, the interactive effects of multiple drivers on species distribution changes are too often neglected by researchers, leading to an overemphasis on the effects of CC. This may have biased our perception, both in science and in the public, of the relative importance of specific drivers, and may represent a major impediment to accurate biodiversity projections and effective conservation.

260 To develop truly integrative global science, we need to better acknowledge correlations and interactions among drivers, in particular CC and LUC, and multiple-driver studies should become the 
norm. The increasing availability of datasets and methods can help overcome the challenges posed by studying multiple processes.

\section{References}

Ameztegui, A., Coll, L., Brotons, L., and Ninot, J.M. (2016). Land-use legacies rather than climate change are driving the recent upward shift of the mountain tree line in the Pyrenees. Glob. Ecol. Biogeogr. 25, 263-273.

Angert, A.L., Crozier, L.G., Rissler, L.J., Gilman, S.E., Tewksbury, J.J., and Chunco, A.J. (2011). Do species' traits predict recent shifts at expanding range edges? Ecol. Lett. 14, 677-689.

Archaux, F. (2004). Breeding upwards when climate is becoming warmer: no bird response in the French Alps. Ibis 146, 138-144.

Bailey, S.-A., Haines-Young, R.H., and Watkins, C. (2002). Species presence in fragmented landscapes: modelling of species requirements at the national level. Biol. Conserv. 108, 307-316.

Barbet-Massin, M., Thuiller, W., and Jiguet, F. (2012). The fate of European breeding birds under climate, land-use and dispersal scenarios. Glob. Change Biol. 18, 881-890.

Benning, T.L., LaPointe, D., Atkinson, C.T., and Vitousek, P.M. (2002). Interactions of climate change with biological invasions and land use in the Hawaiian Islands: Modeling the fate of endemic birds using a geographic information system. Proc. Natl. Acad. Sci. U. S. A. 99, 14246-14249.

Bodin, J., Badeau, V., Bruno, E., Cluzeau, C., Moisselin, J.-M., Walther, G.-R., and Dupouey, J.-L. (2013). Shifts of forest species along an elevational gradient in Southeast France: climate change or stand maturation? J. Veg. Sci. 24, 269-283.

Braunisch, V., Coppes, J., Arlettaz, R., Suchant, R., Zellweger, F., and Bollmann, K. (2014). Temperate Mountain Forest Biodiversity under Climate Change: Compensating Negative Effects by Increasing Structural Complexity. PLoS ONE 9, e97718.

Caplat, P., Cheptou, P. -O., Diez, J., Guisan, A., Larson, B.M.H., Macdougall, A.S., Peltzer, D.A., Richardson, D.M., Shea, K., van Kleunen, M., et al. (2013). Movement, impacts and management of plant distributions in response to climate change: insights from invasions. Oikos 122, 1265-1274.

Caplat, P., Edelaar, P., Dudaniec, R.Y., Green, A.J., Okamura, B., Cote, J., Ekroos, J., Jonsson, P.R., Löndahl, J., Tesson, S.V., et al. (2016). Looking beyond the mountain: dispersal barriers in a changing world. Front. Ecol. Environ. 14, 261-268.

Carlson, T.N., and Traci Arthur, S. (2000). The impact of land use - land cover changes due to urbanization on surface microclimate and hydrology: a satellite perspective. Glob. Planet. Change 25, 49-65.

de Chazal, J., and Rounsevell, M.D.A. (2009). Land-use and climate change within assessments of biodiversity change: A review. Glob. Environ. Change 19, 306-315. 
Christie, K.S., Jensen, W.F., Schmidt, J.H., and Boyce, M.S. (2015). Long-term changes in pronghorn abundance index linked to climate and oil development in North Dakota. Biol. Conserv. 192, 445453.

Clavero, M., Villero, D., and Brotons, L. (2011). Climate Change or Land Use Dynamics: Do We Know What Climate Change Indicators Indicate? PLoS ONE 6, e18581.

Cunningham, S.J., Madden, C.F., Barnard, P., and Amar, A. (2016). Electric crows: powerlines, climate change and the emergence of a native invader. Divers. Distrib. 22, 17-29.

Didham, R.K., Tylianakis, J.M., Gemmell, N.J., Rand, T.A., and Ewers, R.M. (2007). Interactive effects of habitat modification and species invasion on native species decline. Trends Ecol. Evol. 22, 489496.

Eggers, B., Matern, A., Drees, C., Eggers, J., Härdtle, W., and Assmann, T. (2010). Value of semi-open corridors for simultaneously connecting open and wooded habitats: a case study with ground beetles. Conserv. Biol. J. Soc. Conserv. Biol. 24, 256-266.

Eglington, S.M., and Pearce-Higgins, J.W. (2012). Disentangling the Relative Importance of Changes in Climate and Land-Use Intensity in Driving Recent Bird Population Trends. PLoS ONE 7, e30407.

Elmhagen, B., Kindberg, J., Hellström, P., and Angerbjörn, A. (2015). A boreal invasion in response to climate change? Range shifts and community effects in the borderland between forest and tundra. Ambio 44 Suppl 1, 39-50.

Faleiro, F.V., Machado, R.B., and Loyola, R.D. (2013). Defining spatial conservation priorities in the face of land-use and climate change. Biol. Conserv. 158, 248-257.

Fox, R., Oliver, T.H., Harrower, C., Parsons, M.S., Thomas, C.D., and Roy, D.B. (2014). Long-term changes to the frequency of occurrence of British moths are consistent with opposing and synergistic effects of climate and land-use changes. J. Appl. Ecol. 51, 949-957.

Franco, A.M.A., Hill, J.K., Kitschke, C., Collingham, Y.C., Roy, D.B., Fox, R., Huntley, B., and Thomas, C.D. (2006). Impacts of climate warming and habitat loss on extinctions at species' low-latitude range boundaries. Glob. Change Biol. 12, 1545-1553.

Gaüzère, P., Jiguet, F., and Devictor, V. (2016). Can protected areas mitigate the impacts of climate change on bird's species and communities? Divers. Distrib. 22, 625-637.

Gregory, R.D., Strien, A. van, Vorisek, P., Meyling, A.W.G., Noble, D.G., Foppen, R.P.B., and Gibbons, D.W. (2005). Developing indicators for European birds. Philos. Trans. R. Soc. Lond. B Biol. Sci. 360, 269-288.

Gregory, R.D., Willis, S.G., Jiguet, F., Voří̌̌ek, P., Klvaňová, A., van Strien, A., Huntley, B., Collingham, Y.C., Couvet, D., and Green, R.E. (2009). An Indicator of the Impact of Climatic Change on European Bird Populations. PLoS ONE 4, e4678.

Hansen, G., Stone, D., Auffhammer, M., Huggel, C., and Cramer, W. (2016). Linking local impacts to changes in climate: a guide to attribution. Reg. Environ. Change 1-15.

Heller, N.E., and Zavaleta, E.S. (2009). Biodiversity management in the face of climate change: A review of 22 years of recommendations. Biol. Conserv. 142, 14-32. 
Hill, J. k., Collingham, Y. c., Thomas, C. d., Blakeley, D. S., Fox, R., Moss, D., and Huntley, B. (2001). Impacts of landscape structure on butterfly range expansion. Ecol. Lett. 4, 313-321.

Hockey, P.A., and Midgley, G.F. (2009). Avian range changes and climate change: a cautionary tale from the Cape Peninsula. Ostrich 80, 29-34.

Hockey, P.A., Sirami, C., Ridley, A.R., Midgley, G.F., and Babiker, H.A. (2011). Interrogating recent range changes in South African birds: confounding signals from land use and climate change present a challenge for attribution. Divers. Distrib. 17, 254-261.

Hodgson, J.A., Thomas, C.D., Wintle, B.A., and Moilanen, A. (2009). Climate change, connectivity and conservation decision making: back to basics. J. Appl. Ecol. 46, 964-969.

Jørgensen, P.S., Böhning-Gaese, K., Thorup, K., Tøttrup, A.P., Chylarecki, P., Jiguet, F., Lehikoinen, A., Noble, D.G., Reif, J., Schmid, H., et al. (2016). Continent-scale global change attribution in European birds - combining annual and decadal time scales. Glob. Change Biol. 22, 530-543.

Kampichler, C., van Turnhout, C.A.M., Devictor, V., and van der Jeugd, H.P. (2012). Large-Scale Changes in Community Composition: Determining Land Use and Climate Change Signals. PLoS ONE 7, e35272.

Konvicka, M., Maradova, M., Benes, J., Fric, Z., and Kepka, P. (2003). Uphill shifts in distribution of butterflies in the Czech Republic: effects of changing climate detected on a regional scale. Glob. Ecol. Biogeogr. 12, 403-410.

Kuussaari, M., Bommarco, R., Heikkinen, R.K., Helm, A., Krauss, J., Lindborg, R., Öckinger, E., Pärtel, M., Pino, J., Rodà, F., et al. (2009). Extinction debt: a challenge for biodiversity conservation. Trends Ecol. Evol. 24, 564-571.

Lancaster, L.T., Dudaniec, R.Y., Hansson, B., and Svensson, E.I. (2015). Latitudinal shift in thermal niche breadth results from thermal release during a climate-mediated range expansion. J. Biogeogr. 42, 1953-1963.

Lavergne, S., Molina, J., and Debussche, M. (2006). Fingerprints of environmental change on the rare mediterranean flora: a 115-year study. Glob. Change Biol. 12, 1466-1478.

Lavergne, S., Evans, M.E.K., Burfield, I.J., Jiguet, F., and Thuiller, W. (2013). Are species' responses to global change predicted by past niche evolution? Philos. Trans. R. Soc. B Biol. Sci. 368, 20120091.

Lemoine, N., Bauer, H.G., Peintinger, M., and Bohning-Gaese, K. (2007). Effects of climate and landuse change on species abundance in a central European bird community. Conserv. Biol. 21, 495-503.

Lenoir, J., and Svenning, J.-C. (2015). Climate-related range shifts - a global multidimensional synthesis and new research directions. Ecography 38, 15-28.

Lunney, D., Stalenberg, E., Santika, T., and Rhodes, J.R. (2014). Extinction in Eden: identifying the role of climate change in the decline of the koala in south-eastern NSW. Wildl. Res. 41, 22-34.

Maggini, R., Lehmann, A., Kéry, M., Schmid, H., Beniston, M., Jenni, L., and Zbinden, N. (2011). Are Swiss birds tracking climate change?: Detecting elevational shifts using response curve shapes. Ecol. Model. 222, 21-32. 
Mantyka-pringle, C.S., Martin, T.G., and Rhodes, J.R. (2012). Interactions between climate and habitat loss effects on biodiversity: a systematic review and meta-analysis. Glob. Change Biol. 18, 1239-1252.

Maxwell, S.L., Fuller, R.A., Brooks, T.M., and Watson, J.E.M. (2016). Biodiversity: The ravages of guns, nets and bulldozers. Nature 536, 143-145.

Menéndez, R., Megías, A.G., Hill, J.K., Braschler, B., Willis, S.G., Collingham, Y., Fox, R., Roy, D.B., and Thomas, C.D. (2006). Species richness changes lag behind climate change. Proc. R. Soc. Lond. B Biol. Sci. 273, 1465-1470.

O'Connor, R.S., Hails, R.S., and Thomas, J.A. (2014). Accounting for habitat when considering climate: has the niche of the Adonis blue butterfly changed in the UK? Oecologia 174, 1463-1472.

Oliver, T.H., and Morecroft, M.D. (2014). Interactions between climate change and land use change on biodiversity: attribution problems, risks, and opportunities. Wiley Interdiscip. Rev. Clim. Change 5, 317-335.

Ordonez, A., Martinuzzi, S., Radeloff, V.C., and Williams, J.W. (2014). Combined speeds of climate and land-use change of the conterminous US until 2050. Nat. Clim. Change 4, 811-816.

Pagel, J., and Schurr, F.M. (2012). Forecasting species ranges by statistical estimation of ecological niches and spatial population dynamics. Glob. Ecol. Biogeogr. 21, 293-304.

Paprocki, N., Glenn, N.F., Atkinson, E.C., Strickler, K.M., Watson, C., and Heath, J.A. (2015). Changing habitat use associated with distributional shifts of wintering raptors. J. Wildl. Manag. 79, 402-412.

Parmesan, C., and Yohe, G. (2003). A globally coherent fingerprint of climate change impacts across natural systems. Nature 421, 37-42.

Parmesan, C., Burrows, M.T., Duarte, C.M., Poloczanska, E.S., Richardson, A.J., Schoeman, D.S., and Singer, M.C. (2013). Beyond climate change attribution in conservation and ecological research. Ecol. Lett. $16,58-71$.

Péron, G., and Altwegg, R. (2015). Twenty-five years of change in southern African passerine diversity: non-climatic factors of change. Glob. Change Biol.

Popy, S., Bordignon, L., and Prodon, R. (2010). A weak upward elevational shift in the distributions of breeding birds in the Italian Alps. J. Biogeogr. 37, 57-67.

Porzig, E.L., Seavy, N.E., Gardali, T., Geupel, G.R., Holyoak, M., and Eadie, J.M. (2014). Habitat suitability through time: using time series and habitat models to understand changes in bird density. Ecosphere 5, 1-16.

Princé, K., Lorrillière, R., Barbet-Massin, M., Léger, F., and Jiguet, F. (2015). Forecasting the effects of land use scenarios on farmland birds reveal a potential mitigation of climate change impacts. PloS One 10, e0117850.

Reif, J., Storch, D., Voříšek, P., Št́astný, K., and Bejček, V. (2008). Bird-habitat associations predict population trends in central European forest and farmland birds. Biodivers. Conserv. 17, 3307-3319. 
Sirami, C., Brotons, L., Burfield, I., Fonderflick, J., and Martin, J.L. (2008). Is land abandonment having an impact on biodiversity? A meta-analytical approach to bird distribution changes in the northwestern Mediterranean. Biol. Conserv. 141, 450-459.

Stürck, J., Levers, C., Zanden, E.H., Schulp, C.J.E., Verkerk, P.J., Kuemmerle, T., Helming, J., LotzeCampen, H., Tabeau, A., Popp, A., et al. (2015). Simulating and delineating future land change trajectories across Europe. Reg. Environ. Change 1-17.

Suarez-Seoane, S., Osborne, P.E., and Baudry, J. (2002). Responses of birds of different biogeographic origins and habitat requirements to agricultural land abandonment in northern Spain. Biol. Conserv. 105, 333-344.

Tayleur, C., Caplat, P., Massimino, D., Johnston, A., Jonzén, N., Smith, H.G., and Lindström, Å. (2015). Swedish birds are tracking temperature but not rainfall: evidence from a decade of abundance changes. Glob. Ecol. Biogeogr. 24, 859-872.

Thuiller, W., Araújo, M.B., and Lavorel, S. (2004). Do we need land-cover data to model species distributions in Europe? J. Biogeogr. 31, 353-361.

Titeux, N., Henle, K., Mihoub, J.-B., Regos, A., Geijzendorffer, I.R., Cramer, W., Verburg, P.H., and Brotons, L. (2016). Biodiversity scenarios neglect future land-use changes. Glob. Change Biol. 22, 2505-2515.

Verburg, P.H., Soepboer, W., Veldkamp, A., Limpiada, R., Espaldon, V., and Mastura, S.S.A. (2002). Modeling the Spatial Dynamics of Regional Land Use: The CLUE-S Model. Environ. Manage. 30, 391405.

Wang, J., Zhao, Y., Li, C., Yu, L., Liu, D., and Gong, P. (2015). Mapping global land cover in 2001 and 2010 with spatial-temporal consistency at $250 \mathrm{~m}$ resolution. ISPRS J. Photogramm. Remote Sens. 103, 38-47.

Wittwer, T., O'Hara, R.B., Caplat, P., Hickler, T., and Smith, H.G. (2015). Long-term population dynamics of a migrant bird suggests interaction of climate change and competition with resident species. Oikos 124, 1151-1159. 
436 The authors are global change ecologists and conservation ecologists working on a wide range of biological models, ecosystems or countries and at various spatial and temporal scales. They have published numerous papers in high-ranked journals on the effects of climate change and/or land-use

439 change on observed changes in species distribution and abundance. They are also deeply involved in

440 conservation actions and have experienced how detrimental the lack of integration can be on the

441 ground.

442

443 
Table 1. Key words selected based on title and abstracts of a large sample of publications on climate change, land-use change and species distributions. We consulted the Web of Science database (http://www.webofknowledge.com) for the last 15 years (2000-2014). We ran the following searches: LUC-obs = effect of land-use change (LUC) on observed changes; LUC-proj= effects of LUC on projected changes; CC-obs = effects of climate change (CC) on observed changes; CC-proj = effects of CC on projected changes; CC and LUC-obs = effects of both LUC and CC on observed changes; CC and LUC-proj = effects of both LUC and CC on projected changes. We tried to include as many terms as possible related to LUC to include the wide diversity of key words used in these studies. As a result, we believe that our search may have, if anything, only slightly underestimated the number of

\begin{tabular}{|c|c|c|c|c|c|c|}
\hline Key words included & $\begin{array}{l}\text { LUC- } \\
\text { obs }\end{array}$ & $\begin{array}{l}\text { LUC- } \\
\text { proj }\end{array}$ & $\begin{array}{l}\text { CC } \\
\text {-obs }\end{array}$ & $\begin{array}{l}\text { CC } \\
\text {-proj }\end{array}$ & $\begin{array}{l}\text { CC } \\
\text { and } \\
\text { LUC } \\
- \text { obs }\end{array}$ & $\begin{array}{l}\text { CC } \\
\text { and } \\
\text { LUC } \\
\text { - proj }\end{array}$ \\
\hline $\begin{array}{l}\text { Species distribution: "species diversity" } \\
\text { "distribution range*" OR "range expansion*" OR "range } \\
\text { contraction*" OR "distributional shift*" OR "range } \\
\text { shift*" OR "elevation* distribution*" OR "altitudinal } \\
\text { distribution*" OR "latitudinal distribution*" OR "species } \\
\text { distribution*" OR "species abundance*" OR "species } \\
\text { composition" OR "community composition" OR } \\
\text { "population change*" OR "population decline*" OR } \\
\text { "species range*" OR "species richness" }\end{array}$ & $\mathrm{x}$ & $\mathrm{x}$ & $\mathrm{x}$ & $\mathrm{x}$ & $\mathrm{x}$ & $\mathrm{x}$ \\
\hline $\begin{array}{l}\text { Land-use change: "land-use change*" OR "habitat } \\
\text { change*" OR "habitat degradation" OR "habitat loss*" } \\
\text { OR "habitat fragmentation" OR "land use change*" OR } \\
\text { "land cover change*” OR "land abandonment" OR } \\
\text { "agricultural intensification" OR "rural depopulation" } \\
\text { OR "urbanization" }\end{array}$ & $\mathrm{x}$ & $\mathrm{x}$ & & & $\mathrm{x}$ & $\mathrm{x}$ \\
\hline $\begin{array}{l}\text { Climate change: } \\
\text { warming" OR "temperature increase" OR "precipitation } \\
\text { loss" OR "drought" OR "flood" OR "extreme event" }\end{array}$ & & & $\mathrm{x}$ & $\mathrm{x}$ & $\mathrm{x}$ & $\mathrm{x}$ \\
\hline $\begin{array}{l}\text { Observed: "observed" OR "historical" OR “past" OR } \\
\text { "current” }\end{array}$ & $\mathrm{x}$ & & $\mathrm{x}$ & & $\mathrm{x}$ & \\
\hline $\begin{array}{l}\text { Projected: "predict*" OR "project*" OR "scenario" OR } \\
\text { "future" }\end{array}$ & & $\mathrm{x}$ & & $\mathrm{x}$ & & $\mathrm{x}$ \\
\hline $\begin{array}{l}\text { NOT: "Pleistocene" OR "Paleo" OR "fossil" OR } \\
\text { "glacial" OR "quaternary” OR “Holocene” OR "marine" } \\
\text { OR "ocean*" OR "sea" }\end{array}$ & $\mathrm{x}$ & $\mathrm{x}$ & $\mathrm{x}$ & $\mathrm{x}$ & $\mathrm{x}$ & $\mathrm{x}$ \\
\hline
\end{tabular}


459 Figure 1. Temporal variations in 1) the number of publications on the observed (-obs) or projected (460 proj) effects of climate change (CC), land-use change (LUC), and both combined in the same 461 publication (CC-LUC), on species distributions and abundances, and 2) the \% of publications 462 integrating land-use change (LUC) and climate change (CC) in publications on observed (Integration463 obs) and projected (Integration-proj) effects (i.e. percentage of publications including both drivers

464 simultaneously over all publications including either one of the drivers represented along the 465 secondary axis). This figure is restricted to the period 2000-2014 since referencing for years 2015 and 2016 in Web of Science was not complete at the time of the review. This analysis is based on publications title, abstract and keywords.

Figure 2. Level of driver integration in publications on observed changes in species distribution and abundance considering both climate change (CC) and land-use change (LUC) in on our literature search. This analysis is based on publications' full text.

Figure 3. Synthesis of the three major recommendations for effective integrative global change science regarding the study design, data available and methods that can easily be implemented (mustdo). We also suggest several avenues to further improve global change science (wish-list). 
Figure 1.

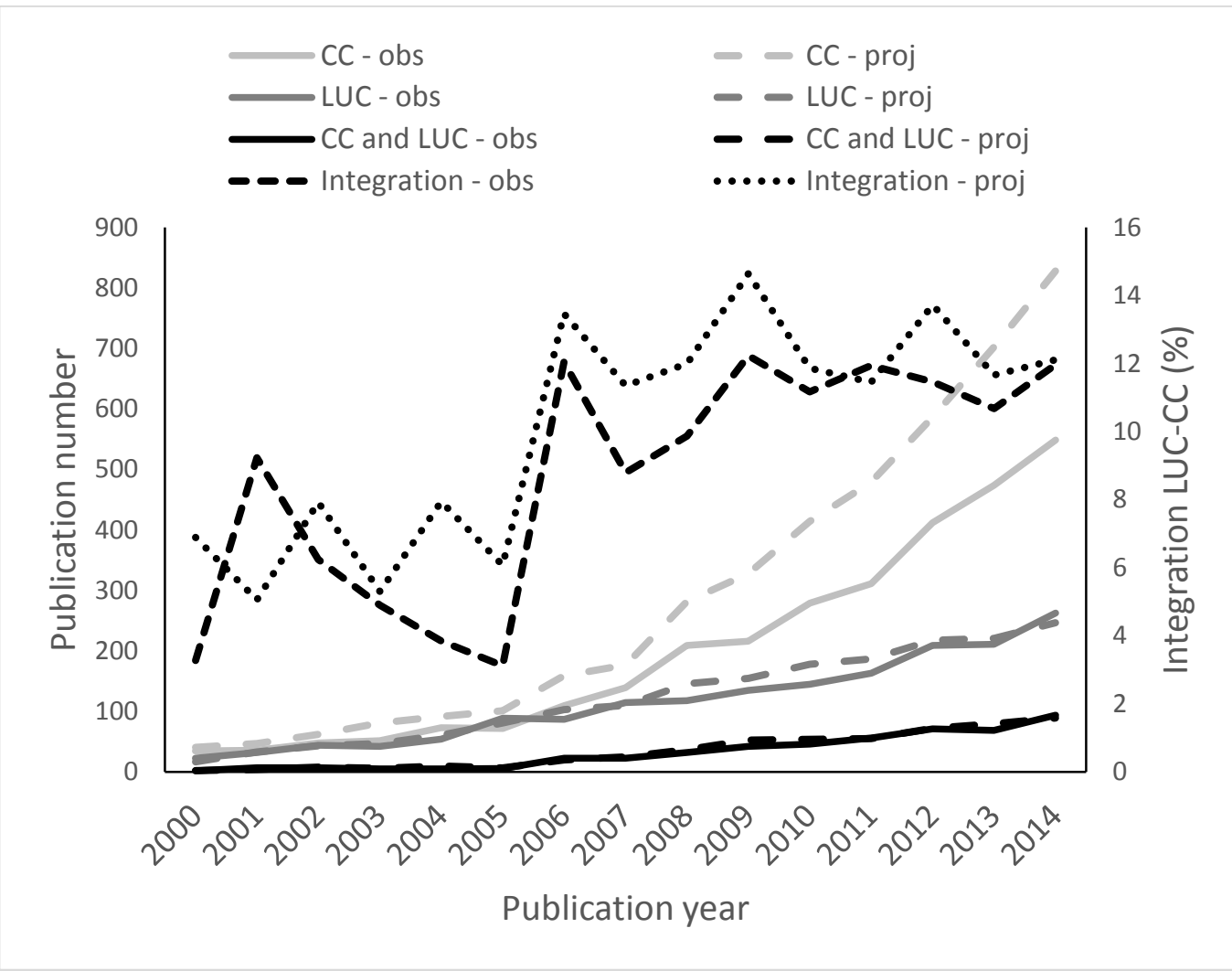

477

478 
Figure 2.

480

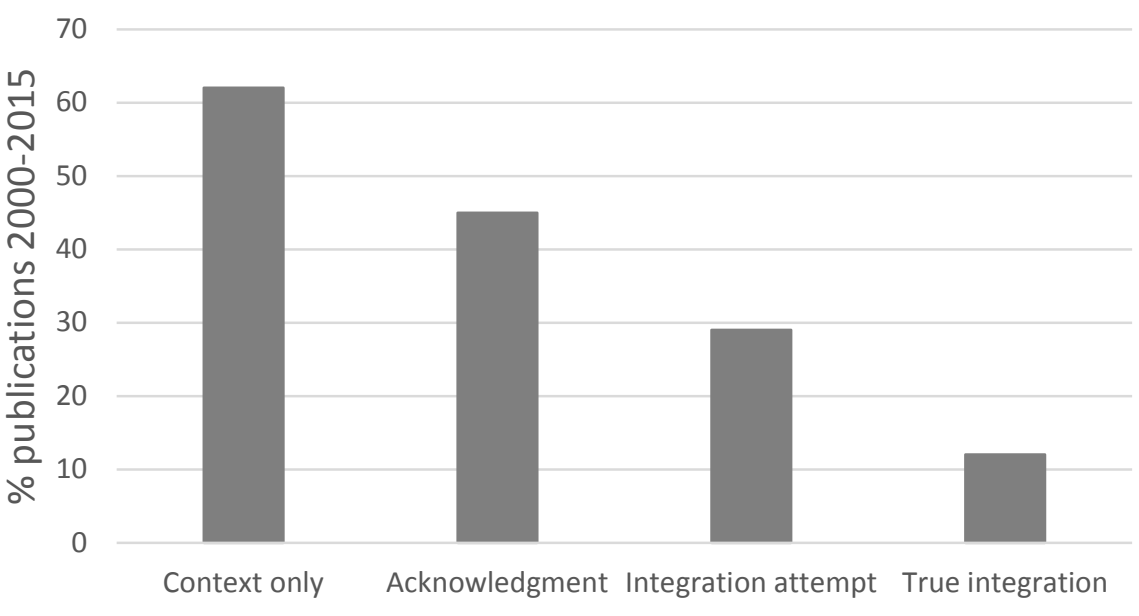

481

482 


\begin{tabular}{|c|c|c|c|}
\hline & 1. Consider multiple drivers & 2. Assess interactions & 3. Question processes at species level \\
\hline Design & $\begin{array}{l}\text { Consider alternative drivers at any scale, in } \\
\text { particular CC and LUC }\end{array}$ & $\begin{array}{l}\text { Consider alternative hypotheses: } \\
\text { confounding, synergystic, antagonistic effects }\end{array}$ & $\begin{array}{l}\text { Consider that species distribution and } \\
\text { requirements result from multiple processes }\end{array}$ \\
\hline Data & $\begin{array}{l}\text { Use available data on multiple drivers } \\
\text { e.g. Stürck et al., } 2015\end{array}$ & $\begin{array}{l}\text { Use long-term monitoring schemes } \\
\text { e.g. NEON }\end{array}$ & $\begin{array}{l}\text { Use and develop community indicators } \\
\text { e.g. CTI - Kampichler et al., } 2012\end{array}$ \\
\hline $\begin{array}{l}\text { Methods } \\
\text { Must-do }\end{array}$ & $\begin{array}{l}\text { Revisit existing datasets and studies } \\
\text { e.g. Péron and Altwegg, } 2015\end{array}$ & $\begin{array}{l}\text { Conduct meta-analysis } \\
\text { e.g. Mantyka-Pringle et al., } 2012\end{array}$ & $\begin{array}{l}\text { Compare guilds or species } \\
\text { e.g. Konvicka } 2003\end{array}$ \\
\hline $\begin{array}{l}\text { Methods } \\
\text { Wish-list }\end{array}$ & $\begin{array}{l}\text { Include more than two drivers } \\
\text { e.g. Benning et al., } 2002\end{array}$ & $\begin{array}{l}\text { Combine methodological approaches } \\
\text { e.g. Tayleur et al., } 2015\end{array}$ & $\begin{array}{l}\text { Include time-lags and adaptation processes } \\
\text { e.g. Menéndez et al., } 2006\end{array}$ \\
\hline
\end{tabular}




\section{Outcomes of publications designed to study the effects of both LUC and CC on species distribution and abundance.s}

\section{Case 1. The effects of LUC overrides the effect of CC}

Eglington and Pearce-Higgins (2012) showed that despite more stable land-use intensity in recent years, climate change has not overtaken land-use intensity as the dominant driver of UK bird populations. Ametzegui et al. (2016) showed that the cessation of human activity drove forest dynamics at the tree line in the Catalan Pyrenees, Spain, and revealed a very low or even negligible signal of climate change in the study area. Similarly, Bodin et al. (2013) showed that the shift of forest species along an elevation gradient in Southeast France resulted from the maturation of forests due to land abandonment rather than climate change. O'Connor et al. (2014) showed that changes to soil surface temperatures caused by increased grazing had a more consistent influence than air temperature increases on the recovery of the Adonis blue butterfly in the UK.

\section{Case 2. LUC and CC impact different sets of species}

Lavergne et al. (2006) showed that changes in land use and climate influenced the occurrence of different plant species in Mediterranean France. Similarly, Hockey et al. (2011) showed that land-use and climate change influenced range shifts of different types of South African bird species. Kampichler et al. (2012) showed that interactions between climate and land-use change differed between habitats for Dutch breeding bird communities. Fox et al. (2014) showed that changes in land use and climate influenced distributional changes of different types of British moths but not all species of a given type behaved similarly, suggesting complex interactions between these two drivers.

\section{Case 3. LUC and CC act in synergy}

Lunney et al. (2014) showed that overwhelming land-use changes (human population growth and habitat loss) have been hiding the significant contribution of climate changes (temperature increase and drought) to the long-term shrinkage in the distribution of the koala in south-eastern New South Wales, Australia. Porzig et al. (2014) showed that temporal variations in Californian birds were best explained by temporal changes in vegetation, but that variations in rainfall also had a significant effect for four of the seven species studied. Christie et al. (2015) showed that temporal variations in pronghorn abundance in North Dakota, U.S.A., were primarily due to variations in winter weather but were also negatively affected by the increase in road and oil/gas well density that has recently increased and is likely to impede pronghorn movement to more hospitable areas during winter storms. Paprocki et al. (2015) showed that temporal changes in wintering raptors populations in southwest Idaho, U.S.A., were influenced by northward distributional shifts due to climate change as well as temporal changes in local habitat conditions. Finally, Cunningham et al. (2016) showed that pied crow numbers in south-western South Africa have increased in response to climate warming, with their spread facilitated by electrical infrastructure. 